\title{
INHERITED FEEDING \\ HABIT OF HERONS
}

\author{
JOHN T. ZMMMER
}

Bureau of Agriculture, Manila, P. I.

$\mathrm{R}^{\mathrm{E}}$ ECENTLY I had the opportunity to observe a very curious habit possessed by two young herons, which was interesting from the standpoint of its possibly hereditary nature as well as for its peculiarity.

The birds belonged to the species Pyrrherodia manilensis (Meyen) and were kept in captivity by Alfred Worm of Manila. At the time in question they were being given their morning meal of partly dried fish, which were thrown to them on the floor of the verandah where the birds were kept. I noticed that they seemed to be having some little difficulty in securing the fish, and that they would peck at each one a number of times before finally obtaining it. Continued observation made it evident that the first efforts invariably fell short of the mark. The consistency of the mistakes in this particular suggested a clue to the explanation. Accordingly, to test out the theory, a few fish were thrown into a basin of water, where they sank to the bottom, and offered to the birds in that state. True to expectation, the herons unerringly picked these fish out of the water at the first attempt.

\section{LIGHT REFRACTION CAUSE OF ERROR}

The explanation which presented itself to me, is based on the refraction of light. The submerged fish appeared to the observers to be somewhat more distant than they actually were, and hence the herons, in order to reach the mark, were obliged to aim at a point appreciably nearer than the apparent position of the object. This they seemed to do as a matter of course.
Since, in a wild state, they would secure most of their food from shallow water, food consisting for a large part of prey which would escape if not obtained at the first attempt, this habit of rectifying the aim, to correct for refraction would be extremely advantageous if not indispensable. In the present case, however, it seemed to be present at the expense of ability to align the stroke in the direction of actual sight or at least to recognize the necessity for such alignment.

\section{UNABLE TO PROFIT BY EXPERIENCE}

An interesting feature of the case was the apparent failure of the birds to profit fully by experience. Although they were able to find each object of search after a series of trials, at the next venture they reverted to their original, deflected aim. The persistence of this action leads me to believe that the habit is an inherited trait. I was told that the herons had been fed occasionally in water, since their capture some three weeks previously, but their rations had been given to them for the most part on the bare floor, and as they were taken from the nest when they were less than a week old, there is little chance that the performance was the result of experience, especially since experience seemed to have so little effect in overcoming the difficulty when circumstances demanded it. Whether or not the young herons will acquire greater proficiency in terrestrial feeding as they grow older, remains to be seen. 